\title{
Apoptosis of liver cancer cells by vitamin K2 and enhancement by MEK inhibition
}

\author{
KAZUYA MATSUMOTO, JUN-ICHI OKANO, TAKAKAZU NAGAHARA and YOSHIKAZU MURAWAKI
}

Second Department of Internal Medicine, Tottori University School of Medicine, 36-1 Nishi-cho, Yonago, Tottori 683-8504, Japan

Received May 23, 2006; Accepted July 17, 2006

\begin{abstract}
Vitamin K2 (VK2) is an anti-proliferative agent toward a variety of cancer including hepatocellular carcinoma (HCC). Because the growth inhibitory effect of VK2 to $\mathrm{HCC}$ has not been established yet, we investigated it in HCC cells in vitro. VK2 inhibited growth of Hep3B, but not of HepG2, HLF, and Huh6. VK2 induced the cell cycle arrest at the G1 phase and involvement of apoptosis was suggested because the sub-G1 fraction appeared in flow cytometric analysis and nuclear condensation and fragmentation appeared after VK2 treatment. VK2 activated extracellular signal-regulated kinase (ERK)1/2 in a mitogen-activated ERK-regulating kinase (MEK)-dependent manner in Hep3B and Huh6, but not in HepG2 and HLF. When ERK1/2 was inhibited by U0126, apoptosis by VK2 in Hep3B, but not in Huh6, was significantly enhanced. However, Western blot analysis revealed that neither apoptosis induction by VK2 nor enhancement of apoptosis by U0126 was mediated by caspase activation. These data demonstrated that VK2 induced apoptosis and activated the MEK/ERK1/2 signaling pathway in a cell-type specific manner, and a MEK inhibitor could augment the cell death in these cells.
\end{abstract}

\section{Introduction}

Hepatocellular carcinoma (HCC) is a leading cause of cancerrelated death in the world. Intensive chemotherapy including intrahepatic administration has been applied for patients with advanced HCC, however, the prognosis of these patients is

Correspondence to: Dr Jun-Ichi Okano, Second Department of Internal Medicine, Tottori University School of Medicine, 36-1 Nishi-cho, Yonago, Tottori 683-8504, Japan

E-mail: okanoj@hotmail.co.jp

Abbreviations: VK2, vitamin K2; HCC, hepatocellular carcinoma; ERK, extracellular signal-regulated kinase; MEK, mitogen-activated ERK-regulating kinase; MTT, 3-(4,5-dimethylthiazol-2-yl)-2,5diphenyltetrazolium bromide; HCC, hepatocellular carcinoma; PI3K, phosphatidylinositol-3-OH kinase

Key words: vitamin K2, extracellular signal-regulated kinase, apoptosis, liver cancer not favorable. Therefore, the development of new drugs for the treatment of advanced HCC is expected to improve the prognosis of these patients.

Vitamin $\mathrm{K}(\mathrm{VK})$ is an essential vitamin existing in three different forms including phylloquinone (VK1) in green leafy vegetables, menaquinone (VK2) produced by the intestinal flora, and menadione (VK3), a synthetic VK congener. The physiological function of $\mathrm{VK}$ is a cofactor of the enzyme $\gamma$-glutamyl-carboxylase, which converts glutamate (Glu) residues into $\gamma$-carboxy glutamate (Gla). Since VK2 has a pivotal role in bone formation (1), VK2 is widely used as a therapeutic drug for osteoporosis in Japan.

It was recently reported that VK2 significantly prevented the development of HCC when applied in the treatment of the patients with liver cirrhosis (2) and suppressed the recurrence of HCC after curative treatment (3). In addition, VK2 has been demonstrated to exert an anti-proliferative action toward a variety of cancer cells including lung carcinoma (4), acute myeloid leukemia cells (5), and HCC cells $(6,7)$. However, the mechanisms by which VK2 inhibit the growth of HCC cells are undefined.

Extracellular signal-regulated kinase (ERK) $1 / 2$ is a signaling molecule relevant to chemoresistance to a variety of drugs (8). In this study, we found that VK2 inhibited the growth of HCC cells and activated the mitogen-activated ERK-regulating kinase (MEK)/ERK1/2 signaling pathway in a cell-type specific manner. A MEK inhibitor sensitized HCC cells to VK2, demonstrating MEK/ERK1/2 as resistant molecules to VK2.

\section{Materials and methods}

Materials. VK2 was kindly provided by Eisai Co., Ltd. (Tokyo, Japan) and dissolved in ethanol as a vehicle. A phosphorylation-independent antibody for ERK1/2 was purchased from Stressgene Biotechnologies Corp. (Victoria, Canada). An antibody specific for ERK1/2 phosphorylated at the Thr202/Tyr204 residues, an anti-ß-actin antibody, and Hoechst 33258 were purchased from Sigma (St. Louis, MO, USA). A mitogen-activated ERK-regulating kinase (MEK) inhibitor, U0126, was purchased from Calbiochem-Novabiochem Corp. (San Diego, CA, USA) and dissolved in DMSO as a vehicle. Anti-caspase-3 and caspase-9 antibodies were purchased from Cell Signaling Technology (Beverly, MA, USA). Secondary anti-mouse and anti-rabbit horseradish peroxidase antibodies were purchased from Amersham Pharmacia Biotechnology 
(Piscataway, NJ, USA). Des- $\gamma$-carboxyprothrombin (DCP) levels produced by HCC cells were measured by LUMIPULSE (Eisai Co., Ltd.).

Cell lines and tissue culture. Hep3B, HepG2, HLF, and Huh6 cells were cultured in Dulbecco's modified Eagle's medium (DMEM) (Invitrogen Corp., Carlsbad, CA, USA), supplemented with $10 \%$ fetal bovine serum (Cosmo Biotechnology, Tokyo, Japan) and penicillin/streptomycin (Cosmo Biotechnology) at $37^{\circ} \mathrm{C}$ in a $5 \% \mathrm{CO}_{2}$ incubator.

Cell viability. Cell viability was assessed by modified 3(4,5-dimethylthiazol-2-yl)-2,5-diphenyltetrazolium bromide (MTT) assays (Cell Counting Kit-8, Dojindo Corp., Kumamoto, Japan) following the supplier's protocol. Briefly, cells were grown in 96 -well plates at $37^{\circ} \mathrm{C}$ in a $5 \% \mathrm{CO}_{2}$ incubator and treated with the compounds. After $10 \mu \mathrm{l}$ of reagent was added, OD450 was measured by a microplate reader (Dade Behring, Deerfield, IL, USA). Control samples always contained $0.1 \%$ ethanol and/or DMSO. The experiments were repeated at least six times and data were expressed as the mean $\pm \mathrm{SD}$.

Hoechst 33258 staining. Cells grown in 8-well slides (Nalgen Nunc International, Rochester, NY, USA) were fixed in methanol/acetic acid (3:1) solution for $15 \mathrm{~min}$, washed with phosphate-buffered saline (PBS) for $5 \mathrm{~min}$ three times, and stained with Hoechst 33258 solution for 20 min under light-protected conditions. The cells were observed under a fluorescent microscope.

Flow cytometry. The cell pellets treated with VK2 were washed with PBS containing $1 \%$ fetal bovine serum, fixed in $70 \%$ ethanol, stained with $0.5 \mathrm{mg} / \mathrm{ml}$ propidium iodide (Sigma) containing 3 Kunitz RNase (Nippon Gene Co., Ltd., Tokyo, Japan), and then analysis was performed with a flow cytometer (EPICS-XL, Beckman Coulter Inc., Miami, FL, USA).

Total protein preparation and Western blotting. Total protein preparation from cells and Western blotting were performed as described previously (9). Briefly, cells were lysed in radio immune precipitation (RIPA) buffer (Upstate, Lake Placid, NY, USA) supplemented with $1 \mathrm{mM}$ sodium orthovanadate, $1 \mathrm{mM}$ phenylmethylsulfonyl fluoride (PMSF), and a protease inhibitor mixture tablet (Roche Diagnostics, Basel, Switzerland) for $10 \mathrm{~min}$ on ice. Total protein samples $(10 \mu \mathrm{g})$ were separated on a sodium lauryl sulfate (SDS)polyacrylamide gel (PAGE) and transferred to a polyvinylidene difluoride (PVDF) membrane (Immobilon-P, Millipore, Bedford, MA, USA). After the membranes were blocked in 5\% non-fat milk (Santa Cruz Biotechnology Inc., Santa Cruz, CA, USA) in TBST (10 mM Tris, $150 \mathrm{mM}$ $\mathrm{NaCl}, \mathrm{pH} 8.0$, and $0.1 \%$ Tween-20) for $1 \mathrm{~h}$ at room temperature, they were probed with primary antibodies overnight at $4^{\circ} \mathrm{C}$, washed three times in TBST, incubated with anti-mouse or anti-rabbit horseradish peroxidase (HRP) antibody in TBST for $1 \mathrm{~h}$ at room temperature. The signals were visualized by a chemiluminescence solution (ECL, Amersham Pharmacia Biotechnology).
A

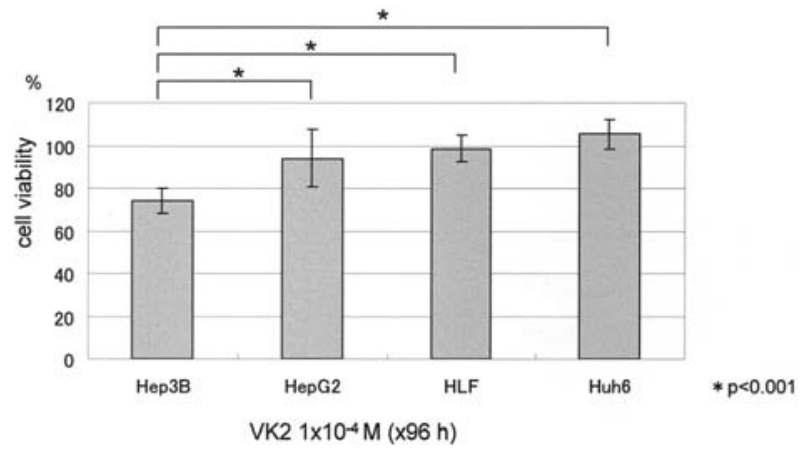

B

\begin{tabular}{|c|c|c|}
\hline \multirow{2}{*}{} & \multicolumn{2}{|c|}{ PIVKA-II level (mAU/ml) } \\
\cline { 2 - 3 } & supernatant & homogenate \\
\hline Hep3B & 526 & 844 \\
\hline HepG2 & 256 & 52353 \\
\hline HLF & 0 & 63 \\
\hline Huh6 & 0 & 6 \\
\hline
\end{tabular}

Figure 1. Effects of VK2 on the proliferation of human liver cancer cells. (A) After Hep3B, HepG2, HLF, and Huh6 cells were treated with $1 \times 10^{-4} \mathrm{M}$ VK2 for $96 \mathrm{~h}$, the cellular growth was examined by MTT assays. OD450 at each time-point was expressed as percentage of untreated cells containing $0.1 \%$ ethanol as a vehicle. These experiments were repeated six times and data are expressed as the mean $\pm \mathrm{SD}$. (B) Des- $\gamma$-carboxyprothrombin (DCP) levels of supernatant and cellular homogenate in HCC cells were demonstrated.

A

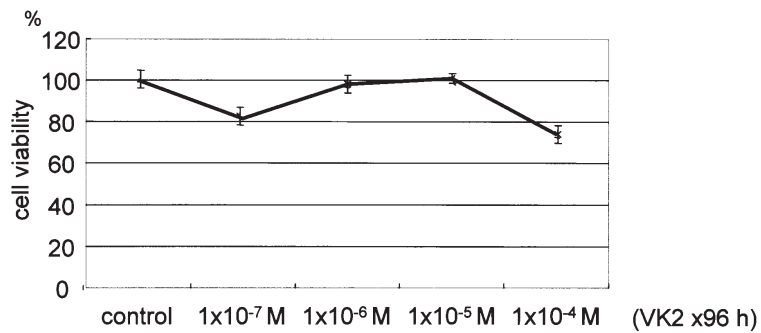

B

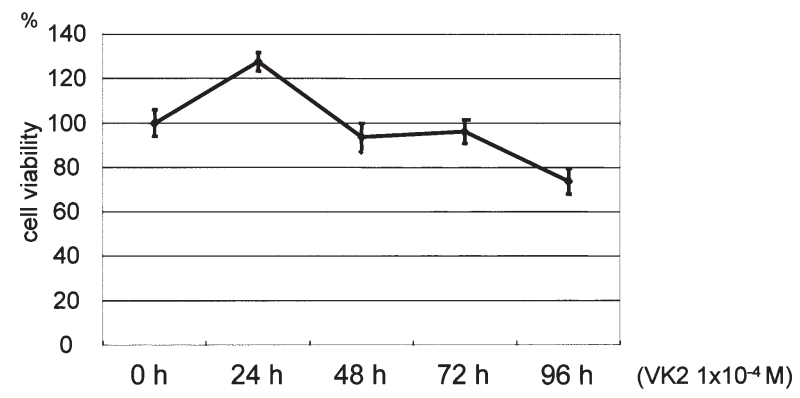

Figure 2. Effects of VK2 on the proliferation of Hep3B cells. (A) MTT assays were performed after Hep3B cells were treated with escalating doses $\left(1 \times 10^{-7}\right.$, $1 \times 10^{-6}, 1 \times 10^{-5}$, and $1 \times 10^{-4} \mathrm{M}$ ) of VK2 for $96 \mathrm{~h}$. (B) MTT assays were performed after Hep3B cells were treated with $1 \times 10^{-4} \mathrm{M}$ VK2 for $24,48,72$, and $96 \mathrm{~h}$. OD450 at each concentration and time point was expressed as percentage of untreated cells containing $0.1 \%$ ethanol as a vehicle. These experiments were repeated six times and data are expressed as the mean \pm SD.

Statistical analysis. Data were expressed as the mean \pm SD. The data of MTT assays were analyzed using the paired t-test to assess differences between experimental groups. Statistical significance was inferred at $\mathrm{p}<0.05$. 


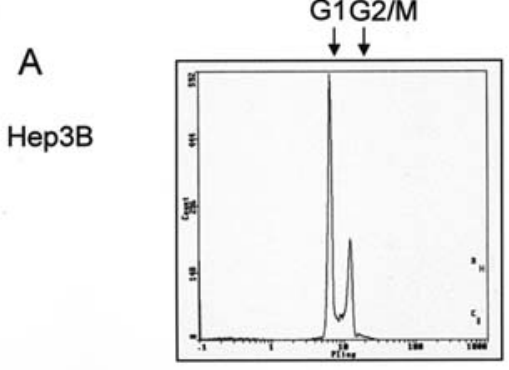

control

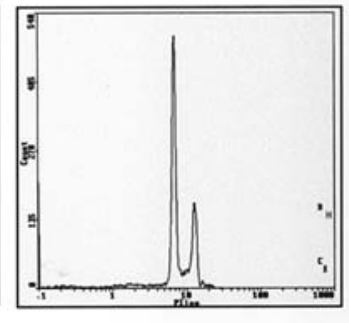

$\mathrm{x} 24 \mathrm{~h}$

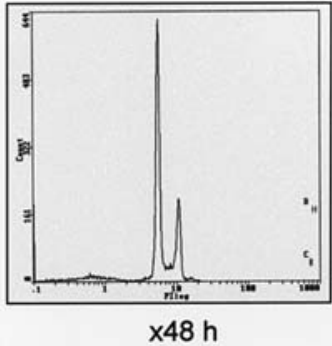

$\mathrm{x} 48 \mathrm{~h}$

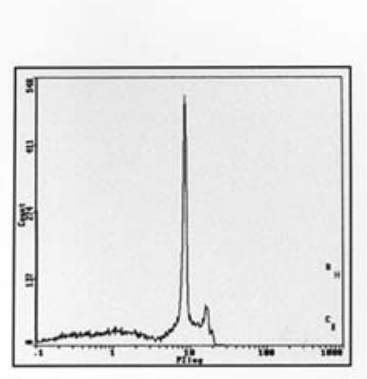

x72 h

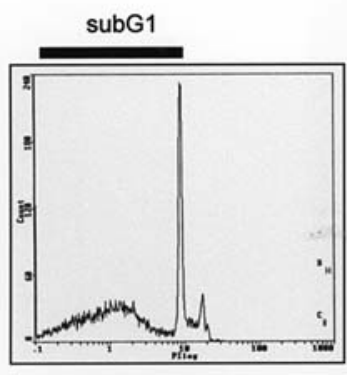

x96 h

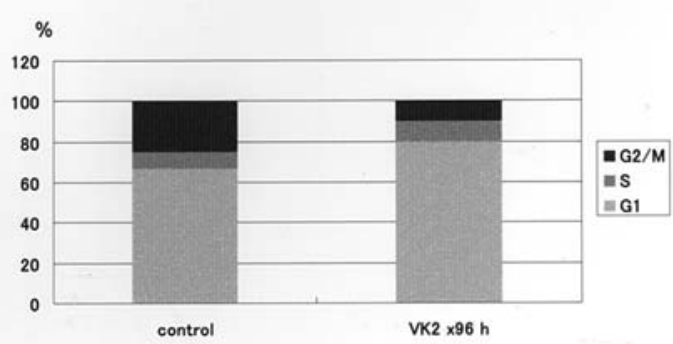

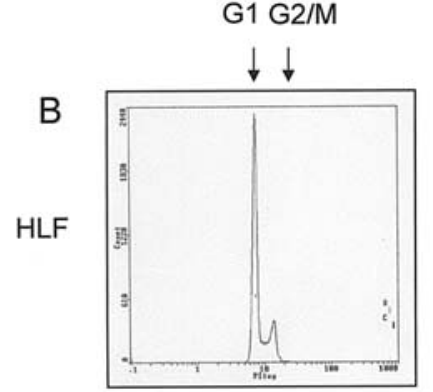

control

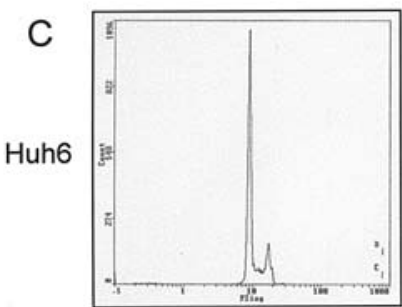

control

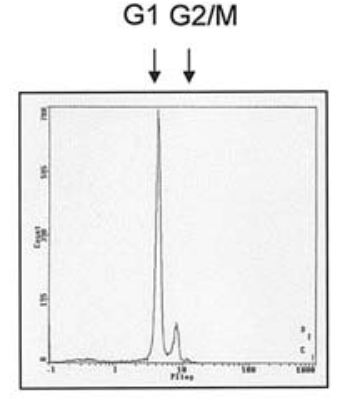

VK2 $1 \times 10^{-4} \mathrm{M}(\mathrm{x} 96 \mathrm{~h})$
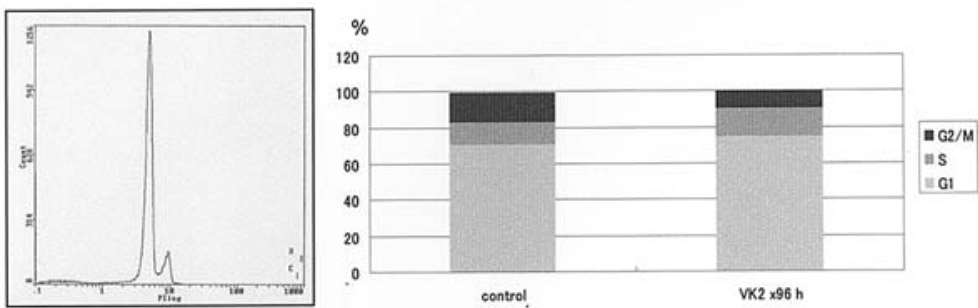

VK2 $1 \times 10^{-4} \mathrm{M}(\mathrm{x} 96 \mathrm{~h})$

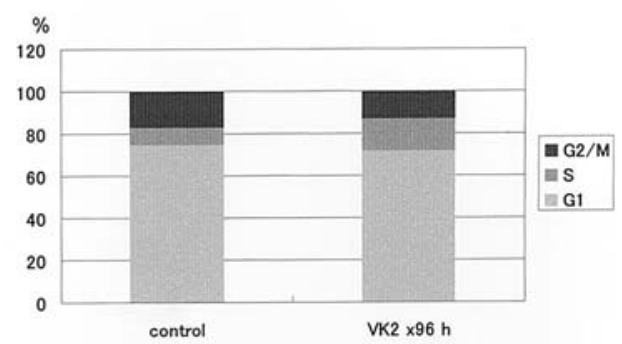

control

VK2 $296 \mathrm{~h}$

Figure 3. Flow cytometric analysis of human liver cancer cells after treatment with VK2. Flow cytometric analysis was performed after Hep3B cells were treated with $1 \times 10^{-4}$ M VK2 for 24, 48, 72, and $96 \mathrm{~h}$ (A). Control cells contained $0.1 \%$ ethanol as a vehicle. Similar experiments were conducted in HLF (B), Huh6 (C), and HepG2 (data not shown) cells. Cellular fraction in G1, S, and G2/M phases after 96 h of the VK2 treatment was summarized as bar graphs.

\section{Results}

Effects of VK2 on the proliferation of liver cancer cells. First, we evaluated the effect of VK2 on the proliferation of human HCC cells cultured under $10 \%$ serum. The growth of HepG2, HLF, and Huh6 was not significantly modulated by the treatment of $1 \times 10^{-4} \mathrm{M} \mathrm{VK} 2$ for $96 \mathrm{~h}$ when compared to untreated cells containing a vehicle $(0.1 \%$ ethanol) (Fig. 1A).
In contrast, the proliferation of Hep3B cells producing DCP (Fig. 1B), resulting from an acquired post-translational defect in the vitamin $\mathrm{K}$-dependent carboxylase system in HCC (10), was significantly inhibited $\sim 75 \%$ by VK2 (Fig. 1A). The growth inhibitory effect of VK2 on Hep3B cells was mostly in dose- and time-dependent manner (Fig. 2). When similar experiments were conducted under serum-free conditions, the results were mostly indistinguishable from the above 


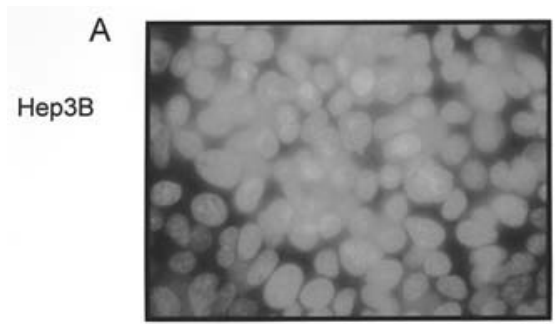

control

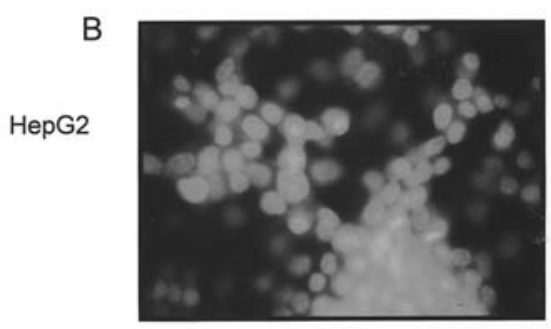

control

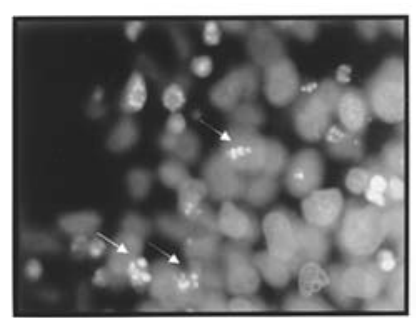

VK2 $1 \times 10^{-4} \mathrm{M}(\times 96 \mathrm{~h})$

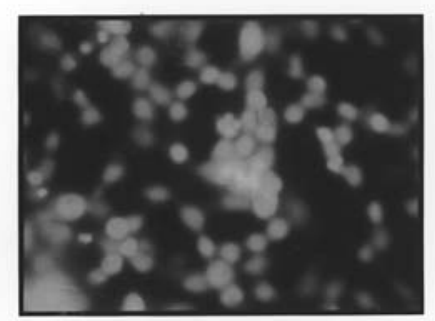

VK2 $1 \times 10^{-4} \mathrm{M}(\mathrm{x} 96 \mathrm{~h})$

C

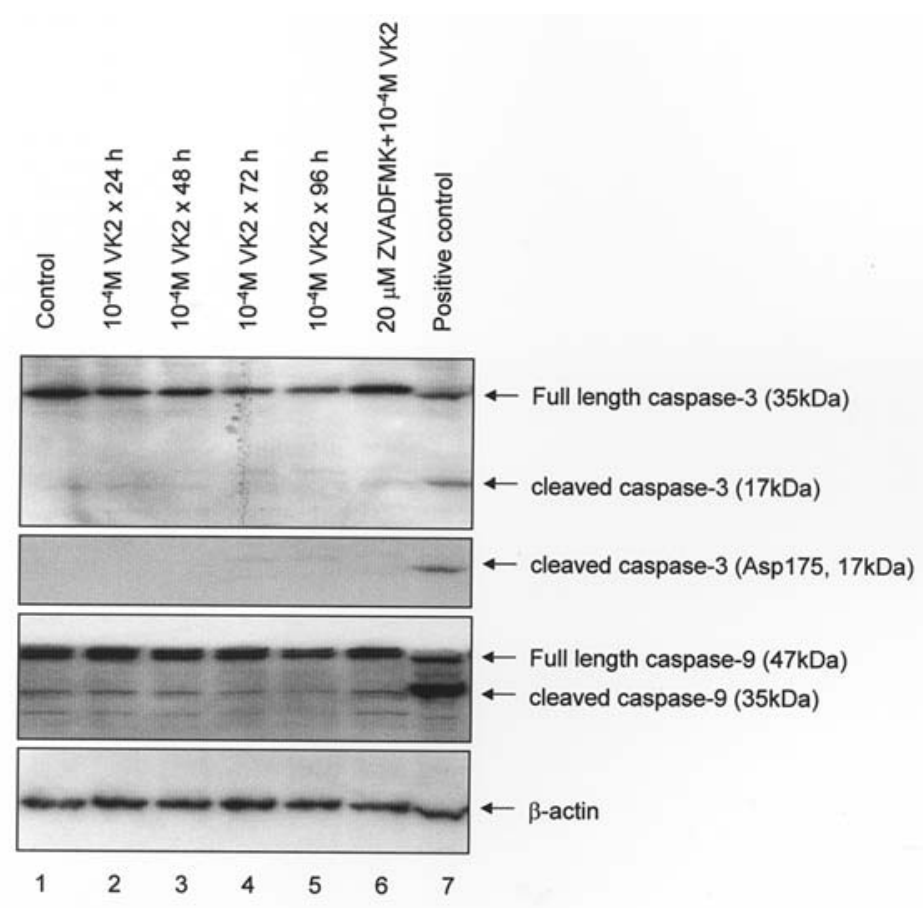

Figure 4. Nuclear morphology of human liver cancer cells after treatment with VK2. Hoechst 33258 staining was performed after Hep3B (A) and HepG2 (B) cells were treated with $1 \times 10^{-4}$ M VK2 for $96 \mathrm{~h}$. Apoptotic cells are indicated by arrows. Original magnification, $\mathrm{x} 400$. (C) Western blot analysis was performed in Hep3B cells treated with $1 \times 10^{-4} \mathrm{M}$ VK2. We employed two types of anti-caspase- 3 antibodies, detecting both full-length ( $\left.35 \mathrm{kDa}\right)$ and cleavedform caspase-3 (17 kDa) (top panel) and only cleaved-form caspase-3 (Asp175, $17 \mathrm{kDa}$ ) (second panel). Activated caspase-9 was detected by anti-caspase-9 antibody recognizing both full-length $(47 \mathrm{kDa})$ and cleaved-form caspase-9 $(35 \mathrm{kDa})$ (third panel). Cell lysates from Daudi cells treated with interferon- $\alpha$ served as a control (lane 7).

(data not shown). These data indicate that VK2 inhibited the growth of HCC cells in a cell-type specific manner independently of DCP status.

Effects of VK2 on the cell cycle and apoptosis. We next evaluated the effect of VK2 on the cell cycle machinery in HCC cells. Flow cytometric analysis revealed that the cell cycle was blocked at the G1 phase after $72 \mathrm{~h}$ of the VK2 treatment in Hep3B cells. In addition, the sub-G1 fraction, a hallmark of apoptosis, was observed after $48 \mathrm{~h}$ of the $1 \times 10^{-4} \mathrm{M}$ VK2 treatment in a time-dependent manner in Hep3B cells (Fig. 3A). In contrast, neither the cell cycle arrest nor the sub-G1 fraction was observed in HLF (Fig. 3B), Huh6 (Fig. 3C), and HepG2 (data not shown) cells.

Induction of apoptosis was confirmed by nuclear morphology after HCC cells were treated with VK2. VK2 induced nuclear shrinkage, condensation, and fragmentation, which are indicative of apoptosis, in Hep3B cells (Fig. 4A). In 
A
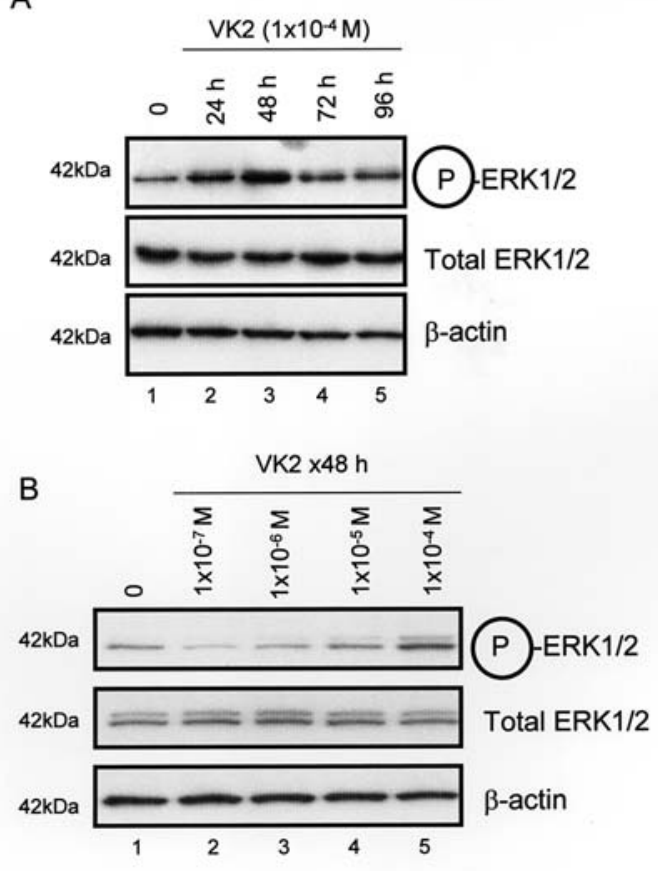

C
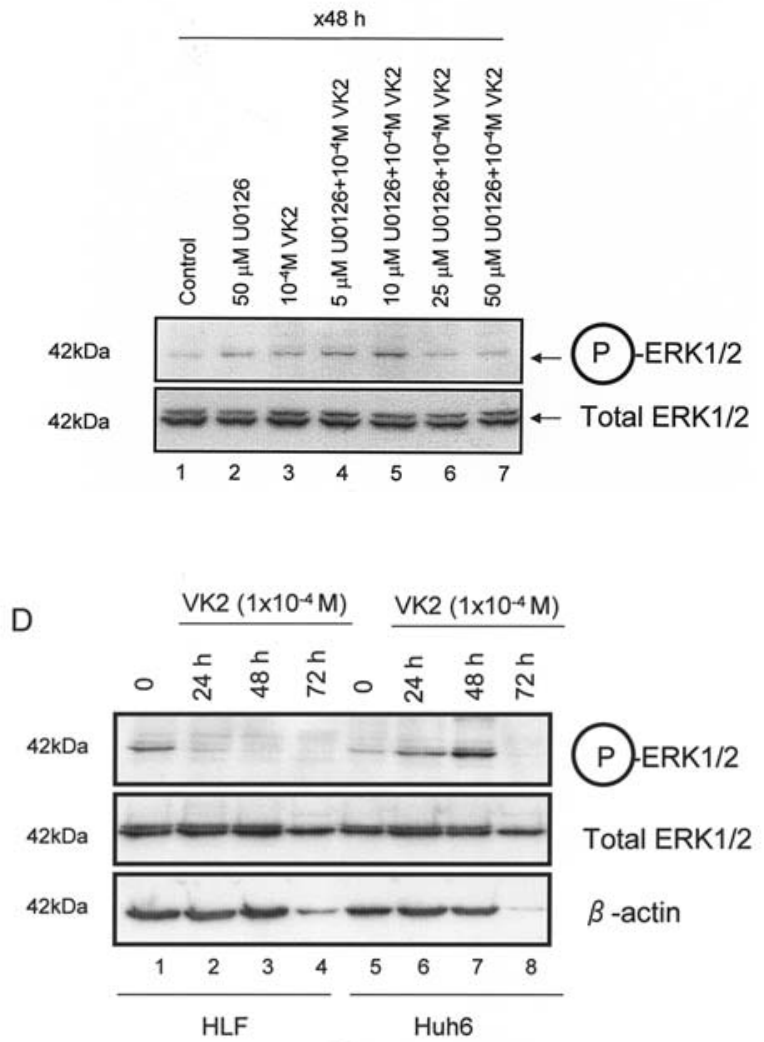

Figure 5. ERK1/2 activation by VK2 in human liver cancer cells. Activation of ERK1/2 was evaluated after treatment of HCC cells with VK2 by Western blot analysis employing a phosphorylation-specific antibody of ERK1/2. The membranes were reprobed with antibodies of total ERK1/2 and B-actin as loading control. (A) Hep3B cells were treated with $10^{-4} \mathrm{M}$ VK2 for 24 , 48,72 , and $96 \mathrm{~h}$ and Western blotting was performed with indicated antibodies. (B) Hep3B cells were treated with escalating doses of VK2 $\left(1 \times 10^{-7}\right.$, $1 \times 10^{-6}, 1 \times 10^{-5}$, and $1 \times 10^{-4} \mathrm{M}$ ) for $48 \mathrm{~h}$ and Western blotting was performed with indicated antibodies. (C) Western blot analysis was performed including Hep3B cells pretreated with escalating doses of $\operatorname{U0126}(5,10,25$, and $50 \mu \mathrm{M})$ before administration of $1 \times 10^{-4} \mathrm{M}$ VK2 for $48 \mathrm{~h}$. (D) HLF and Huh6 cells were treated with $10^{-4} \mathrm{M}$ VK2 for 24, 48 , and $72 \mathrm{~h}$ and Western blotting was performed with indicated antibodies. contrast, apoptosis was not induced in HepG2 (Fig. 4B), HLF, and Huh6 cells (data not shown). These data revealed that growth inhibition of Hep3B cells by VK2 was mediated by induction of apoptosis.

We further evaluated the involvement of caspases in VK2-induced apoptosis in Hep3B cells. We did not observe significant cleavage of caspase-3, an executioner caspase, or caspase-9, an initiator caspase, after treatment with VK2 (Fig. 4C). Cell death induced by VK2 was not reversed by pretreatment with $20 \mu \mathrm{M} \mathrm{Z-VAD-FMK}$, a pan-caspase inhibitor (data not shown). These data indicate that VK2 induced apoptosis in Hep3B cells without activation of caspases.

Roles of ERK1/2 on the VK2-induced apoptosis. Since ERK1/2 and AKT have been linked to the regulation of cellular growth, apoptosis, and chemoresistance (8), we investigated how these signaling molecules are regulated by VK2 in HCC cells. ERK1/2 activity was significantly enhanced by the treatment with $1 \times 10^{-4}$ M VK2 in Hep3B cells, peaking after $48 \mathrm{~h}$ (Fig. 5A). ERK1/2 activation by VK2 was observed in dose-dependent (Fig. 5B) and MEKdependent manner (Fig. 5C). ERK1/2 activation by VK2 was recapitulated in Huh6 cells, but not in HLF (Fig. 5D) and HepG2 (data not shown) cells. AKT activity of these HCC cells was not significantly modulated after treatment with VK2 (data not shown).

To ascertain a role of ERK1/2 activation by VK2 in Hep3B cells, MTT assays, flow cytometric analyses, and Hoechst 33258 staining were performed after pretreatment with U0126, a MEK inhibitor. Treatment with U0126 alone inhibited the growth of Hep3B cells about $80 \%$ compared to the control cells containing vehicle (Fig. 6A), implying that basal ERK1/2 activity was necessary for the growth of Hep3B cells. When the cells were pretreated with U0126 for $30 \mathrm{~min}$ followed by VK2 for $96 \mathrm{~h}$, the cell death was enhanced in an additive manner (Fig. 6A). Flow cytometric analyses revealed that pretreatment with escalating doses of U0126 enhanced the sub G1 fraction induced by VK2 (Fig. 6B). Hoechst 33258 staining demonstrated nuclear condensation and fragmentation after pretreatment of Hep3B cells with U0126 (Fig. 6C). Enhancement of VK2-induced apoptosis by U0126 was not mediated by activation of caspases, because Western blot analysis revealed no active products of caspase- 3 and caspase- 9 after pre-treatment of Hep3B cells with escalating doses of U0126 followed by VK2 (Fig. 6D). In Huh6 cells revealing ERK1/2 activation by VK2 (Fig. 5D), pretreatment with U0126 did not sensitize Huh6 cells to VK2 when evaluated by MTT assays, flow cytometric analysis, and Hoechst 33258 staining (Fig. 6E). These results demonstrate that roles of ERK activation by VK2 are distinct depending on the cell type.

\section{Discussion}

Anti-proliferative action of VK2 has been reported in a variety of cancer cells including lung carcinomas (4), acute myeloid leukemia cells (5), and HCC cells $(6,7)$. However, the mechanisms by which VK2 inhibited the growth of these cancer cells are largely unknown. Our present study demonstrated that VK2 inhibited the growth of HCC cells via 


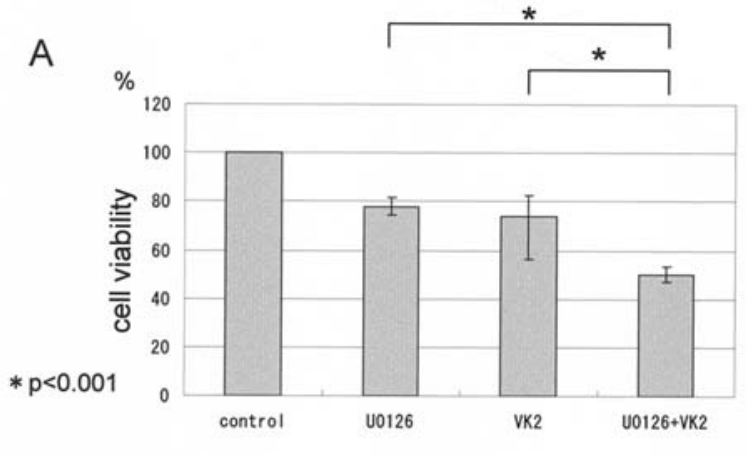

B

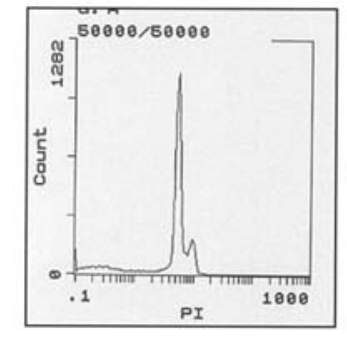

$0.1 \% \mathrm{DMSO}+\mathrm{EtOH}$

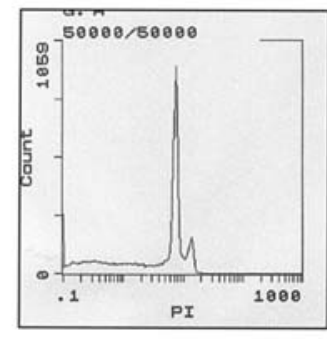

$5 \mu \mathrm{M} \cup 0126+10^{-4} \mathrm{M}$ VK2
C

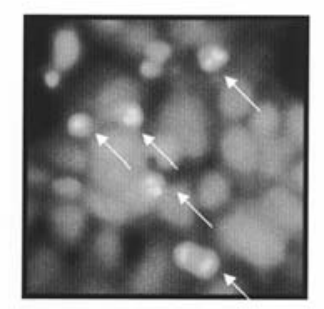

$50 \mu \mathrm{M}$ U0126+VK2 $1 \times 10^{-4} \mathrm{M}(\times 96 \mathrm{~h})$

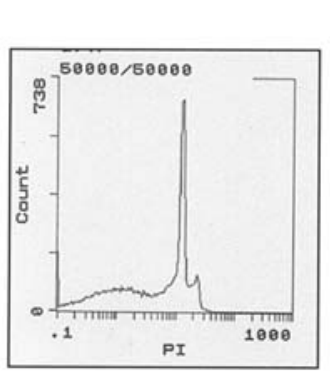

$25 \mu \mathrm{M} \cup 0126+10^{-4} \mathrm{M}$ VK2

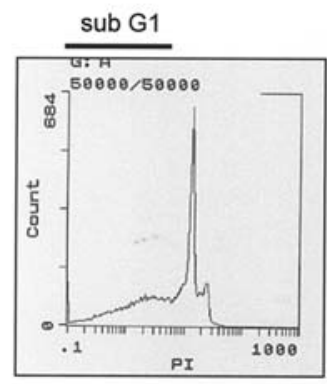

$50 \mu \mathrm{M} \cup 0126+10^{-4} \mathrm{M}$ VK2

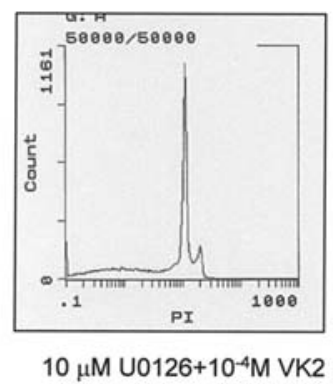

D

$\mathrm{x} 48 \mathrm{~h}$

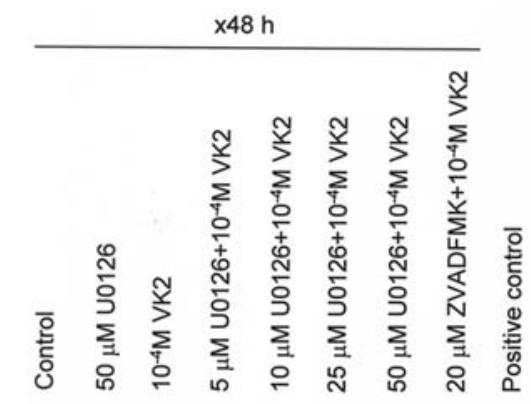

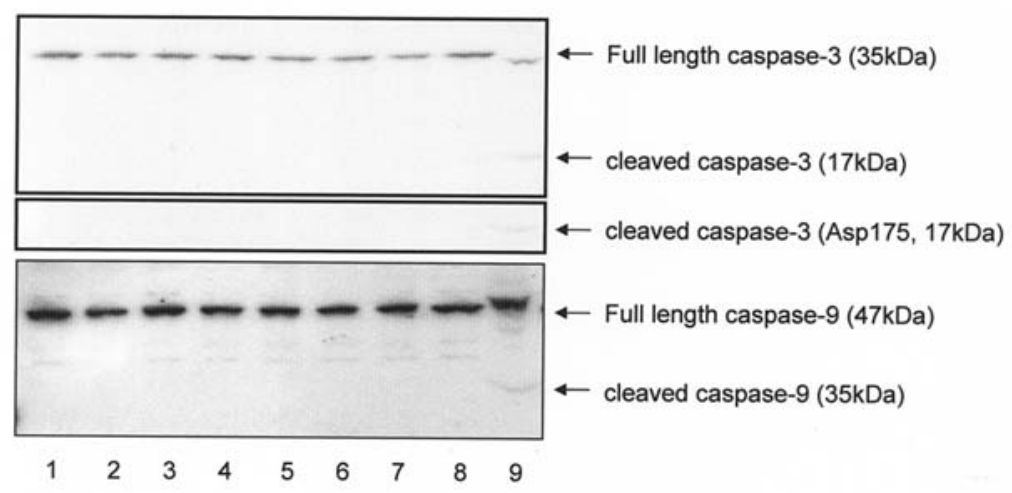




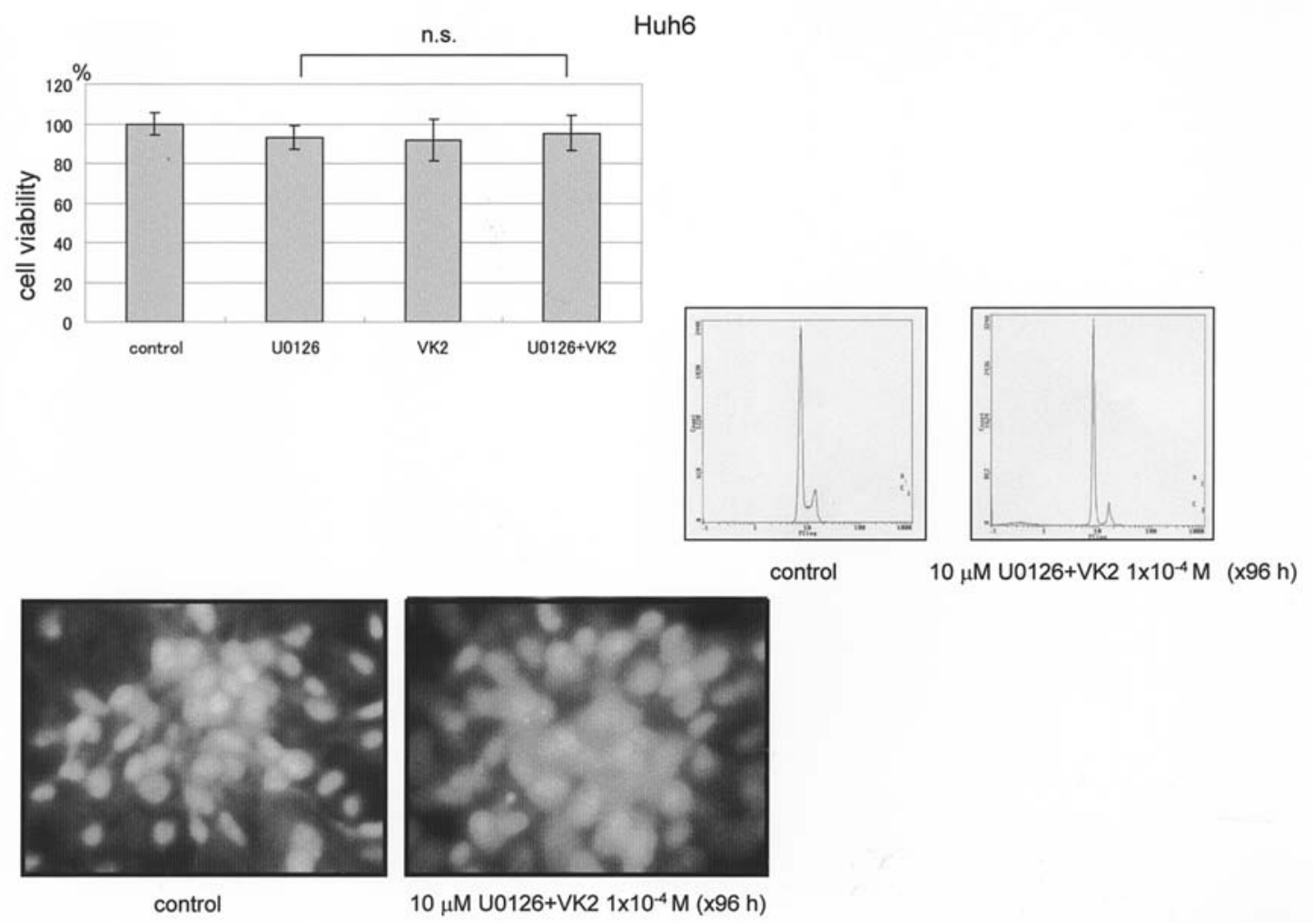

Figure 6. Effects of a MEK inhibitor on the cellular growth and apoptosis in human liver cancer cells. (A) MTT assays were conducted after Hep3B cells were treated with $10 \mu \mathrm{M} \mathrm{U} 0126,1 \times 10^{-4} \mathrm{M} \mathrm{VK} 2$, and pretreated with $10 \mu \mathrm{M}$ U0126 for 30 min followed by $1 \times 10^{-4} \mathrm{M}$ VK2 for $96 \mathrm{~h}$. OD450 was expressed as percentage of untreated cells containing $0.1 \%$ ethanol and DMSO as vehicles. These experiments were repeated six times and data are expressed as the mean \pm SD. (B) Flow cytometric analysis was performed after Hep3B cells were treated with $1 \times 10^{-4} \mathrm{M}$ VK2 alone and pretreated with escalating doses of U0126 (5, 10,25 , and $50 \mu \mathrm{M}$ ) for 30 min followed by $1 \times 10^{-4} \mathrm{M}$ VK2 for $96 \mathrm{~h}$. (C) Hoechst 33258 staining was performed after Hep3B cells were pretreated with $50 \mu \mathrm{M}$ U0126 for $30 \mathrm{~min}$ followed by $1 \times 10^{-4} \mathrm{M} \mathrm{VK} 2$ for $96 \mathrm{~h}$. Apoptotic cells are indicated by arrows. Original magnification, x400. (D) Western blot analysis was performed utilizing Hep3B cells pretreated with escalating doses of $\mathrm{U} 0126(5,10,25$, and $50 \mu \mathrm{M})$ before administration of $1 \times 10^{-4} \mathrm{M}$ VK2 for $48 \mathrm{~h}$ and probed with anti-caspase-3 antibodies, detecting both full-length (35 kDa) and cleaved-form caspase-3 (17 kDa) (top panel), detecting only cleaved-form caspase-3 (Asp175, $17 \mathrm{kDa}$ ) (second panel), and anti-caspase-9 antibody recognizing both full-length (47 kDa) and cleaved-form caspase-9 (35 kDa) (bottom panel). Cell lysates from Daudi cells treated with interferon- $\alpha$ served as a control (lane 9). (E) MTT assays (top panel), flow cytometric analysis (middle panel), and Hoechst 33258 staining (bottom panel, original magnification, $\mathrm{x} 400$ ) were performed after Huh6 cells were pretreated with $10 \mu \mathrm{M} \mathrm{U} 0126$ for 30 min followed by $1 \times 10^{-4} \mathrm{M}$ VK2 for $96 \mathrm{~h}$. In MTT assays, OD450 was expressed as percentage of untreated cells containing $0.1 \%$ ethanol and DMSO as vehicles.

induction of apoptosis in a cell type-specific manner. Because tumor vitamin $\mathrm{K}$ content has a critical role in the synthesis of DCP (11), we evaluated whether the secretion of DCP was correlated to the sensitivity of HCC cells to VK2. Although a limited number of cell lines was analyzed, the antiproliferative effect of VK2 appeared to be independent of the secretion of DCP, because the growth inhibitory effect of VK2 was not ubiquitously observed in DCP-producing cells, concordant with a previous report (6).

Plasma concentration of VK2 achievable in human is about $10^{-5} \mathrm{M}(12)$. In the present study, the growth inhibitory effect of VK2 was observed when a higher concentration $\left(10^{-4} \mathrm{M}\right)$ of VK2 was exposed to the cells for a long period $(96 \mathrm{~h})$, and was limited to a subset of HCC cells. These results suggest that anti-proliferative action of VK2 in HCC cells may be relatively weak and may be observed in limited HCC cells. For clinical application of VK2 in patients with HCC, dosing with higher VK2 concentration must be considered.

Next, we examined the mechanisms by which HCC cells resisted VK2. ERK1/2 is a signaling molecule involved in the regulation of cell survival (13) and sensitivity to chemotherapeutic agents (8) either in a positive (14) or in a negative
(15) manner depending on the cellular context. We observed that VK2 activated ERK1/2 in Hep3B and Huh6 cells. ERK1/2 activation by a VK analogue, Cpd5, in Hep3B cells has been reported (16), demonstrating a positive role of ERK1/2 activation in growth inhibition. On the contrary, we found that U0126, a MEK inhibitor, enhanced apoptosis in Hep3B cells revealing that the MEK/ERK molecules as resistant factors against VK2-induced apoptosis, and that U0126 did not sensitize Huh6 cells to VK2. Thus, the roles of activated ERK1/2 could be complicated and distinct depending on the cellular context.

Caspases are established players of apoptosis in various models, however, increasing recent evidence demonstrated induction of apoptosis without caspase activation (17). In our model, induction of apoptosis was indicated in Hep3B cells after treatment with VK2 and apoptosis was augmented by abrogation of U0126, however, we did not observe activation of caspases, suggesting that caspase-independent pathways are involved in these situations.

To sensitize cancer cells to VK2, combinatory treatment with cisplatin and imatinib mesylate has been challenged in lung cancer cells $(4,18)$. Since our results demonstrated 
that HCC cells were relatively resistant to VK2, and U0126 accelerated cell death in a limited HCC cell lines, a combinatory treatment with a MEK inhibitor and VK2 may benefit some patients with HCC. In addition, identification of new target molecules responsible for the resistance to VK2 is important for clinical application of VK2 in patients with HCC.

\section{Acknowledgements}

This work was partially supported by Japan Society for the Promotion of Science (JSPS), KAKENHI [Grant-in-Aid for Young Scientists (B); 15790346].

\section{References}

1. Tabb MM, Sun A, Zhou C, Grun F, Errandi J, Romero K, Pham H, Inoue S, Mallick S, Lin M, Forman BM and Blumberg B: Vitamin K2 regulation of bone homeostasis is mediated by the steroid and xenobiotic receptor SXR. J Biol Chem 278: 43919-43927, 2003.

2. Habu D, Shiomi S, Tamori A, Takeda T, Tanaka T, Kubo S and Nishiguchi S: Role of vitamin K2 in the development of hepatocellular carcinoma in women with viral cirrhosis of the liver. JAMA 292: 358-361, 2004

3. Mizuta T, Ozaki I, Eguchi Y, Yasutake T, Kawazoe S, Fujimoto K and Yamamoto K: The effect of menatetrenone, a vitamin K2 analog, on disease recurrence and survival in patients with hepatocellular carcinoma after curative treatment: a pilot study. Cancer 106: 867-872, 2006.

4. Yokoyama T, Miyazawa K, Yoshida T and Ohyashiki K: Combination of vitamin K2 plus imatinib mesylate enhances induction of apoptosis in small cell lung cancer cell lines. Int J Oncol 26: 33-40, 2005

5. Miyazawa K, Yaguchi M, Funato K, Gotoh A, Kawanishi Y, Nishizawa Y, Yuo A and Ohyashiki K: Apoptosis/ differentiationinducing effects of vitamin K2 on HL-60 cells: dichotomous nature of vitamin K2 in leukemia cells. Leukemia 15: 1111-1117, 2001.

6. Otsuka M, Kato N, Shao RX, Hoshida Y, Ijichi H, Koike Y, Taniguchi H, Moriyama M, Shiratori Y, Kawabe T and Omata M: Vitamin K2 inhibits the growth and invasiveness of hepatocellular carcinoma cells via protein kinase A activation. Hepatology 40: 243-251, 2004.
7. Wang Z, Wang M, Finn F and Carr BI: The growth inhibitory effects of vitamins $\mathrm{K}$ and their actions on gene expression. Hepatology 22: 876-882, 1995.

8. MacKeigan JP, Collins TS and Ting JP: MEK inhibition enhances paclitaxel-induced tumor apoptosis. J Biol Chem 275: 38953-38956, 2000

9. Okano J, Matsumoto K, Nagahara T and Murawaki Y: Gefitinib and the modulation of the signaling pathways downstream of epidermal growth factor receptor in human liver cancer cells. J Gastroenterol 41: 166-176, 2006.

10. Weitz IC and Liebman HA: Des-gamma-carboxy (abnormal) prothrombin and hepatocellular carcinoma: a critical review. Hepatology 18: 990-997, 1993.

11. Huisse MG, Leclercq M, Belghiti J, Flejou JF, Suttie JW, Bezeaud A, Stafford DW and Guillin MC: Mechanism of the abnormal vitamin K-dependent gamma-carboxylation process in human hepatocellular carcinomas. Cancer 74: 1533-1541, 1994.

12. Shino M, Yamashiro T, Yamada K, Mori Y, Sato T, Kawabe K and Okada K: Determination of menaquinone-4 in plasma after administration of menaquinone-4 dosage forms in healthy human subjects. Yakugaku Zasshi 102: 651-658, 1982.

13. Wada T and Penninger JM: Mitogen-activated protein kinases in apoptosis regulation. Oncogene 23: 2838-2849, 2004.

14. Agazie Y, Ischenko I and Hayman M: Concomitant activation of the PI3K-Akt and the Ras-ERK signaling pathways is essential for transformation by the V-SEA tyrosine kinase oncogene. Oncogene 21: 697-707, 2002.

15. Tsukada Y, Miyazawa K and Kitamura N: High intensity ERK signal mediates hepatocyte growth factor-induced proliferation inhibition of the human hepatocellular carcinoma cell line HepG2. J Biol Chem 276: 40968-40976, 2001.

16. Adachi T, Kar S, Wang M and Carr BI: Transient and sustained ERK phosphorylation and nuclear translocation in growth control. J Cell Physiol 192: 151-159, 2002.

17. Mareninova OA, Sung KF, Hong P, Lugea A, Pandol SJ, Gukovsky I and Gukovskaya AS: Cell death in pancreatitis: caspases protect from necrotizing pancreatitis. J Biol Chem 281: 3370-3381, 2006.

18. Yoshida T, Miyazawa K, Kasuga I, Yokoyama T, Minemura K, Ustumi K, Aoshima M and Ohyashiki K: Apoptosis induction of vitamin K2 in lung carcinoma cell lines: the possibility of vitamin K2 therapy for lung cancer. Int J Oncol 23: 627-632, 2003. 